\title{
Mobile Technologies as Support of Travelling of People with Disabilities
}

\author{
Jan Trejbal / Josef Zelenka \\ e-mail: tobous.trejbal@gmail.com, josef.zelenka@uhk.cz
}

Department of Recreology and Tourism, Faculty of Informatics and Management, University of Hradec Králové, Hradec Králové, Czech Republic

Trejbal, J., \& Zelenka, J. (2019). Mobile Technologies as Support of Travelling of People with Disabilities. Czech Journal of Tourism, 8(1), 65-79. DOI: 10.2478/cjot-2019-0005.

\begin{abstract}
The purpose of this paper is to make conceptual analysis support of the travelling of people with disabilities by using mobile technologies. Based on the conducted qualitative research, an analysis of the requirements for LBSs (local based services) to support the safe travel of people with health disabilities in the context of price and energy consumption optimization has been done. It was accompanied by the conceptual analysis of the use of the LBS to support the safe travel for people with disabilities in both individual and collective tourism. The concept of the application, which will fulfil all discussed requirements, was created. It is based on the analysis of the requirements for safe travel of disabled persons, analysis of available mobile technologies, and analysis of dynamic health assessment options by using neural networks. The presented concept includes the key components of a solution: procedures for reactive and preventive care and individualization of the system settings according to the specific needs.
\end{abstract}

\section{Keywords}

disabilities, social responsibility, mobile technologies, accessible tourism, neural networks, smartphones

JEL classification: L83, L86 


\section{Introduction}

There are many varied trends in tourism, related mainly to social, geopolitical, economic and technological changes in society. One such significant technological factor, which substantially changes tourism, is the development of information and communication technologies (ICT; Zelenka, 2012; Law, Buhalis, \& Cobanoglu, 2014). They affect not only the quality of tourism services and the way of presenting and distributing tourism services and products (e.g., Zelenka, 2012), but they also support the preparation of tourists for travel and their own travelling (Law, Buhalis, \& Cobanoglu, 2014). The quality, scope of services and the rate of use of local based services (LBSs) are on their rise. In addition to the local context, LBSs also use time and user contexts, and their social context is significant too, as their content is often created/complemented by the social networking community. Typical examples are geosocial networks, especially Google+ Local, Foursquare, and Facebook Nearby. LBSs, according to Xiang, Tussyadiah, and Buhalis (2015), and Tussyadiah and Zach (2012), change the experience and experiences of a travel actor and integrate information, ordering and paying for it, communication, entertainment, social networking and other travel support services. LBSs also provide significant support for the travel of people with different types of physical or mental disabilities.

In tourism, the social responsibility of tourists, residents, tourism subjects and destination management is manifested largely in the frames of different approaches, e.g., information and analytical, system, compensation, preventive, delegation, educational (Pásková \& Zelenka, 2016; 2018). With an increasing social responsibility, a growing role of social media (Leung et al., 2013; Nezakati et al., 2015), democratization of the society, support of the United Nations (rights of people with disabilities, see UN, 2006), the European Union (EU), and governments, and tourism industry interest, the tourism of people with disabilities is developed as one of the major trend in tourism (see Figure 1).

In accordance with the globally declared rights of people with disabilities on personal mobility (UN, 2006, article 20) and sports and recreational activities (UN, 2006, article 30), Yau, McKercher, and Packer (2004) note that people with disabilities have the same need to travel as healthy people. In addition, travel and recreational activities can make a significant contribution to the health of disabled people, as Armitano et al. (2015) illustrate by the benefits of surfing for the disabled. Qualitative and quantitative development of the travel of people with disabilities is a significant trend in tourism (Small \& Darcy, 2010; Gillovic \& McIntosh, 2015) and according to Small and Darcy (2010), three basic approaches are applied to disability: medical approach (this corresponds to the focus of the present article), social approach and embodiment. According to Gillovic and McIntosh (2015), it is necessary to examine readiness for accessible tourism at nationwide level. Furthermore, Bizjak, Knežević, and Cvetrežnik (2011) state that it is also necessary to prepare students of tourism schools for the provision of specific services and communication with people with disabilities, and according to Kim, Stonesifer, and Han (2012), also to prepare hotel staff and hotel management. 
Figure 1 Key effects supporting the travelling of people with disabilities

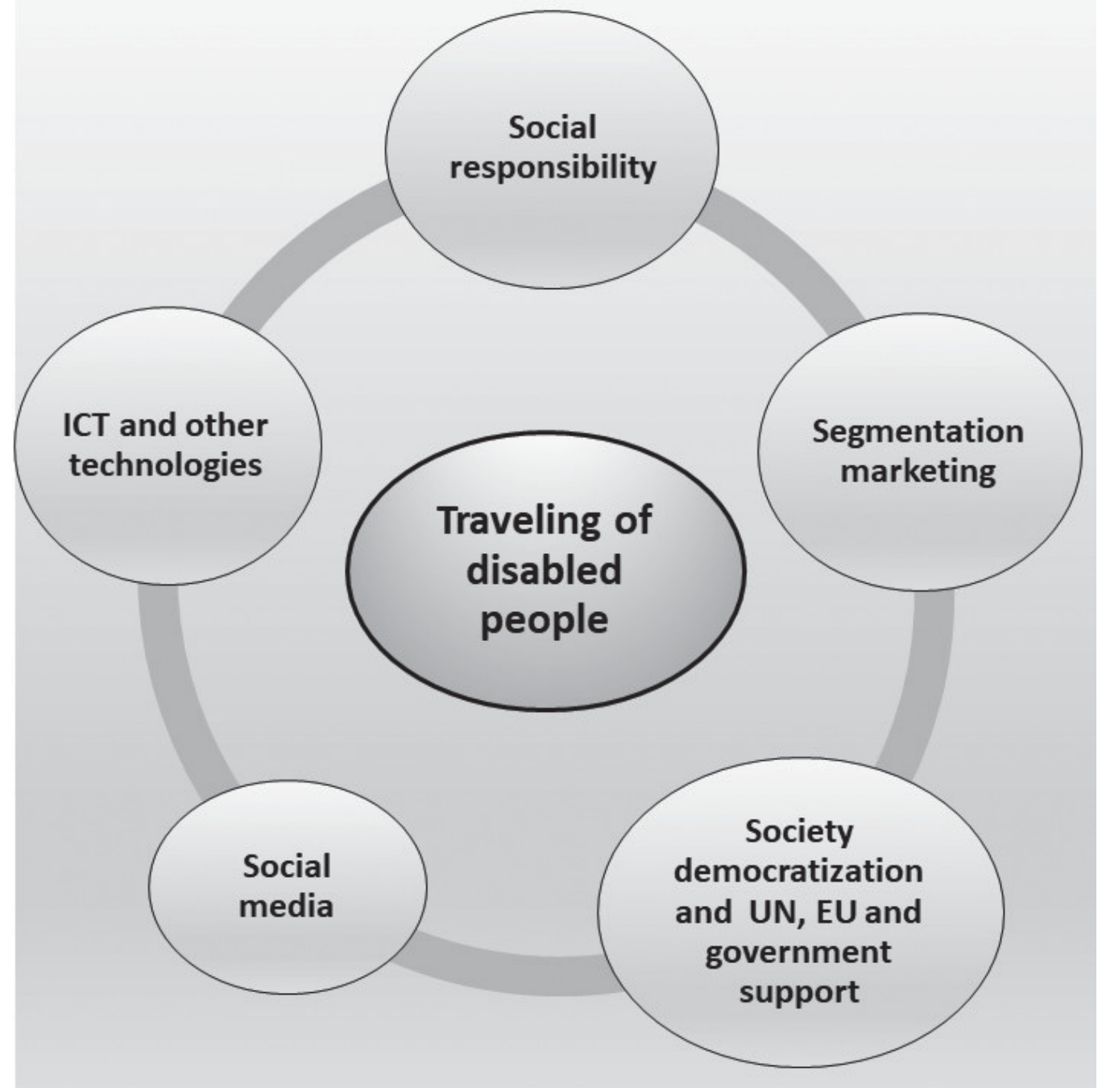

Source: own processing

Although literature most often refer to the travel of people with reduced mobility (including wheelchair users; e.g., Darcy, 2010), the complex perception of people with disability include people with other somatic and psychosomatic problems, people with mental disability, and also people with limited social contacts. The somatic and psychosomatic problems include, in addition to the limited mobility (Yau, McKercher, \& Packer, 2004), also sensory disabilities (especially vision, weak eyesight and blindness, Yau, McKercher, \& Packer, 2004), environmental and food allergies, age-related diseases and potentially life-threatening conditions (cardiovascular, asthmatic, or nervous). In particular, a group of people with disabilities with potentially occurring conditions that significantly endanger the quality of life and possibly, the life is the main target of authors' conceptual research, the results of which are presented in this article. An integral part of the authors' presented solution will also be the provision of information needs 
for all people with disabilities. This is mentioned as an important part of the support for the travel of people with disabilities by Eichhorn et al. (2008), Darcy (2010), and Buhalis and Michopoulou (2011).

\section{Literature Review}

\section{Travelling of people with disabilities}

Research on the travel of people with disabilities is focused on their motivation to travel (Ray \& Ryder, 2003; Figueiredo, Eusébio, \& Kastenholz, 2012; Shi, Cole, \& Chancellor, 2012) and the basic framework of their specific needs (Shaw \& Coles, 2004). They also examine their specific catering and accommodation needs (Ray \& Ryder, 2003; Darcy, 2010; Kim, Stonesifer, \& Han, 2012), transport aspects (e.g., needs of disabled air passengers - Chang \& Chen, 2012; price aspects of transport - Oxley \& Richards, 1995), navigation and field movement (including urban landscapes) and within buildings of tourism and other infrastructure (Small, Darcy, \& Packer, 2012; Mothiravally et al., 2014). Specific attention is paid to the analysis of the impact of different types of disability on travelling motivation (Figueiredo, Eusébio, \& Kastenholz, 2012), on perception during travel and experiences (visual impairment - Small, Darcy, \& Packer, 2012), the benefits of travelling for the disabled and the constraints associated with the disability (visually impaired - Richards, Pritchard, \& Morgan, 2010; Small, Darcy, \& Packer, 2012). The aim of research in the world also includes the social and psychological aspects of travelling of people with disabilities, in particular:

- How travel agents can mediate their travel (McKercher et al., 2003);

- How they experience obstacles (psychological, social, and physical) of travelling and recreation (Smith, 1987);

- How to theoretically describe the context of various limiting factors and the intention to travel (Lee, Agarwal, \& Kim, 2012);

- How people with different disabilities perceive travel experiences and services - e.g., Kim, Stonesifer, and Han (2012) conducted research on hotels, and Small, Darcy, and Packer (2012) among visually impaired persons.

In connection with the significant development of travelling of people with disabilities, the sectoral or regional preparedness of destination management, tourism services providers and other tourism stakeholders are being researched for this type of visitors with specific needs. Such research was carried out in Turkey by Ozturk, Yayli, and Yesiltas (2008) for hotels and travel agencies, with Turkey's hotel and travel management business being ready to develop this new segment (different results for New Zealand see Gillovic \& McIntosh, 2015). Interesting are the results of the comparison of the time spent by people without disabilities and with disabilities on travelling. If people with disabilities participate in tourism, Pagan (2012) does not find any significant differences in the intensity of their involvement in tourism. All these results show how important 
it is to further develop the support of travelling of people with disabilities, including technological support.

To help people with disabilities to travel, different approaches focusing on the human factor, technical measures in the open air, technical measures within the infrastructure of tourism and buildings, transport and the development of individual aids and means used by persons with disabilities are used. Human factor development includes, besides training staff in psychosocial skills (contact, communication, and respect), the acquisition of knowledge for the preparation of appropriate diet with regard to eating difficulties, as well as health care provided when needed. ICT is important for:

- Detailed preparation of the itinerary, finding and ordering (off and online) of services tailored to specific needs;

- Navigation in the field, even for people with visual impairment;

- Emergency assistance;

- Providing advice and support to a wider community and finding people with similar interests, needs (social media);

- Assistance in case of health problems and in particular, prevention of these problems.

\section{Relevant knowledge of hardware for LBSs}

Smartphones are the successors of 'simple' mobile phones with enhanced functionality and their own operating system (OS). The most common OS for smartphones today is Android, iOS or Windows Phone (formerly Windows Mobile). At present, these are essentially portable compact computers where only two of many different functions are calling and sending SMS. In addition, some sensors (such as accelerometers, gyroscopes) and modules for several forms of communication - Wi-Fi, Bluetooth or GSM, are also included. The performance of smartphones is sufficient to conduct more complicated calculations using data from these devices and for more complex network communications. It is therefore possible to use these devices for many other activities, which, in relation to the application described below, support people with disabilities through monitoring activities and health of the user. For a mobile part of the LBSs system that would be responsible for an individual user, the smartphone offers the ability to collect sensory and other user data and to effectively analyze and evaluate the immediate state of health.

Another device important for the system itself is tablet. The operating system can be mobile (the same as on smartphones) or desktop (windows). The benefit of the tablet use within the proposed system lies in its large screen. It offers a much clearer graphical display and is therefore ideal for tracking individual users and their status.

One of the main concepts for such support applications is the context of the user as a link between individual information. It is therefore important to put the user's information into the context and be able to determine the context. This information 
corresponds to the user's position, movement and other relevant information (e.g., heart rate and breath). The current context in this situation therefore corresponds to how an individual user feels as far as his/her health is concerned at that specific moment and is determined by the relationship between the individual data and its values.

\section{Dynamic evaluation of the state of health by using neural networks}

Artificial neural networks (UNN) are branches of artificial intelligence, which are used in a wide variety of disciplines. These fields are typically image recognition, understanding and translating of written or spoken speech and autonomous drones or cars. UNNs are dynamic adaptive algorithms to tackle various issues whose main strength is the ability to learn and adapt to a changing environment. They work on the function approximation principle - input numerical values are mapped to certain outputs. These outputs depend on how the network itself is trained. By training (learning) the network, it is possible to change the result values of the function and adapt the algorithm to solve the new or the changed problem. There are many types of these networks. The most prominent are the forward neural network (see Figure 4) that promotes values towards the output only, and a recursive neural network where the outputs are connected to the inputs, and thus are a form of memory.

The use of neural networks to recognize the health status of the user (and its context) is very promising due to the characteristics of these algorithms and could help to support users with specific needs in the field of tourism. Several neural networks to evaluate different situations could be used in this case.

One of the specific uses of UNN in the proposed system is the detection of falls. With this feature, the neural network receives data from device sensors (usually an accelerometer and a gyroscope), and is able to tell when the user is about to fall or when the user has fallen down. For this, a traditional forward neural network can be used (see Figure 4). The second option is a recurring neural network because it contains memory. The previous values affect what kinds of outputs the recurring neural network will have. It is thus able to monitor the overall development of the user's movement (not only its individual position in the space) and thereby detect his/her abnormal movement.

\section{Methodology}

The conceptual research based on qualitative research (semi structured interviews with three health care and two information technology experts) and technological development is aimed at designing a conceptual and technical solution of the LBSs system, which will support the safe travel of people with health disabilities in both individual and collective tourism, independently or with the involvement of other actors of tourism and using monitoring, long-term knowledge development and artificial intelligence evaluation. Because of this research, the following requirements of the system were established: 
- The proposed LBSs system should work in individual tourism as a silent observer who would collect and evaluate online the location, status and status of the user, inform the user about it, and in the event of an emergency, it would be able to call for help.

- In organized collective tourism, a responsible person (typically a tour manager or a delegate of a travel agency) would be part of the conceptual solution.

- The proposed LBSs system would therefore have a reactive (timely and optimized response to a health crisis) and, in particular, a predictive ability (avoiding dangerous situations degrading the quality of life, or even endangering a participant in tourism).

The current concept of the system has been called WatchDog and its details were developed within the internal university project for support of people with disabilities. The focus of the article is therefore a description of the concept and the way in which it could be used in tourism. The theoretical part of the article focuses on the technical and scientific aspects related to the concept itself in the context of the travelling of people with disabilities. This is mainly a general description of neural networks as a whole and their potential use in the technical solution itself. Most of the concept description deals with the mobile part of the concept since this part is crucial and contains most of the logic of the overall solution. The result of this study is the technical and conceptual solution of the given issue. The article does not address the logistical and managerial aspect of the problem.

\section{Results}

The application concept for the support of the travelling of people with disabilities was developed as an extension of the system for the support of not self-sufficient and ill persons, with the addition of functions necessary for tourism. The system was created from a simple application that only tracked the user's location to a mobile device containing artificial intelligence and the ability to contextualize. It was subsequently expanded by a server component that serves to store data for a long-term evaluation. For the LBSs concept of tourism, a responsible person component has been added that allows a person to manage and have information about a group of people and the ability to respond to their health problems. In addition, some requirements on the mobile part and the server have been expanded for LBSs in the field of tourism.

\section{Conceptual use of the LBSs system to support the safe travelling of people with disabilities in both individual and collective tourism}

In individual tourism, it would be sufficient to install the app on one's own smartphone and set it up. Except for the links to the crisis telephone numbers, it should not be necessary to set it for individual countries - this should be partly autonomous. This 
application would then work without a server, and the responsible person accompanying the person with a disability would be a guard who would try to prevent the crises and call for help if they were to occur.

Mass (and individual tourism in the case of ordering this service, e.g., in hotels) would also use other elements, i.e. the server and facilities of the responsible person. The mobile part would be located on the smartphones of individual tourists, while a responsible person (typically a travel agent guide or a delegate, a hotel staff member, a spa facility, a cruise ship) to instantly display status, location and other information about the participants would use the tablet. In this way, this person would have an overview of the status of the participants and could adapt the program of their stay or tour, or to provide assistance immediately.

\section{Requirements for the LBSs system}

During the development of the system itself (WatchDog), several basic requirements have been defined and they must be met to ensure the required functionality. The concept of implementing this system for the use of LBSs in tourism has expanded these requirements by several points that were not necessary in the original system, but are important for tourism. These new requirements include, for example, an extension to the ability to monitor through a responsible person, and the requirement to offer basic system functions beyond civilization, where GSM data coverage is missing. A list of all basic functions and requirements imposed on the LBSs system is as follows:

- Ability to detect the user context.

- Based on this context, to detect the unexpected or dangerous situation correctly.

- To be able to identify the deteriorating health condition in the long term (days).

- Not to restrict users in normal behavior.

- To work a reasonable time (optimizing energy consumption).

- Not to drastically increase the costs for the routine operation.

- Not to restrict basic functions beyond civilization.

- To provide real-time patient status information for a responsible person.

- To work with little or no need to develop own hardware (HW).

\section{Conceptual and technical solution to one's own LBSs system}

The proposal itself consists of a mobile device that is constantly monitoring the user's status, analyzing critical data, and responding immediately to health threatening situations with selected alert forms. Another part is a server for a data storage and for a long-term evaluation. This evaluation may indicate, in particular, the deterioration of the user's status over a longer time horizon (hours or days) and does not require a realtime response. The last part is the terminal, which is a device that communicates infor- 
mation about individual users to a responsible person, allowing for timely response. The relationship and responsibility of each component of the system is illustrated graphically in Figure 2.

Figure 2 Relationship and responsibility of individual system components

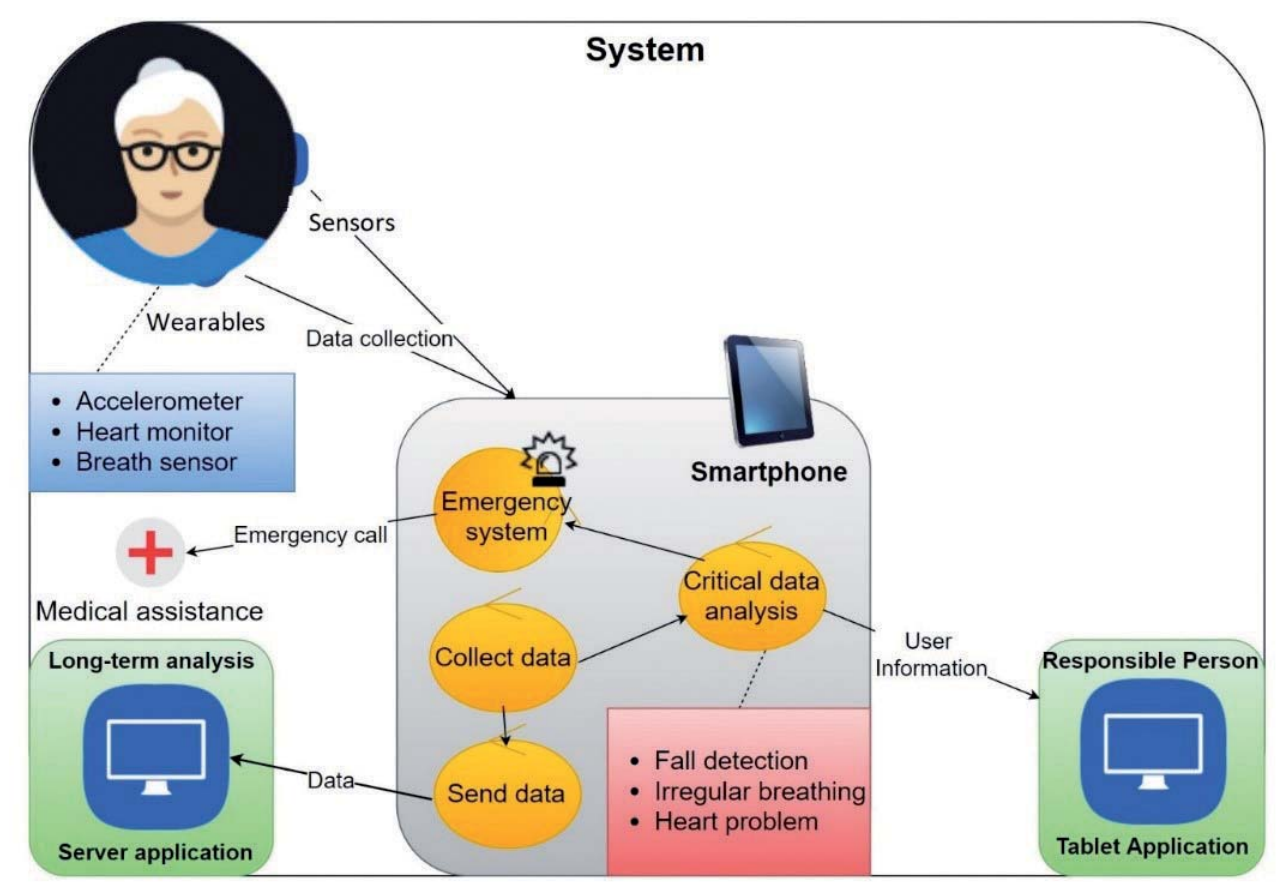

Source: own processing

\section{Mobile part}

The task of the mobile part of the system as the basic component of the system is the collection and evaluation of critical data, the evaluation of dangerous situations and the transmission of information to other elements of the entire ecosystem. Due to the efficiency of deployment, the mobile part of the solution is designed as a smartphone application that has several communication options and built-in sensors. It consists of two parts. The key is the system core containing application logic, evaluation algorithms, and all key functions. The sub-part is a specific layer for smartphones, which is the GUI, application boot logic, HW access and other features, representing the core of the core encapsulation in the OS smartphone environment. The bulk of the application runs in the background to minimize the user and only a fraction of the functionality (mostly settings) is located in the application interface. The core itself is a multiplatform. It is conceived as much as possible independently of the device and can be transferred across different OSs without any major interference and transferred to its own HW. 
The basic functionality of the application consists of several periodic functions that are performed at certain time intervals, independently of each other (Figure 3). One of them is the periodic collection of data from all sensors set up into samples. The sample always matches all sensor values at a certain time. These are stored in two buffers for further processing; each sample being in both trays. Another function is the evaluation, which runs again periodically and once in a given time, the buffer is evaluated by analytical functions (neural networks, dedicated algorithms). The results of the evaluation are sent to the person responsible and, in case of imminent danger, the safety elements of the system are activated. The sensory and support data are also sent to the server for a deeper analysis of the long-term context. For cases where the user is out of the internet coverage, there is a fuse in the system in the form of a local database (operating on the FIFO principle). In this database, the data are stored and sent to the server after the connection is restored.

The core of the application consists of several basic components. The basic behavior of the system controls the basic component where the application logic is located. The component interaction and application logic is shown in Figure 4. The basic components of the system are:

- Two buffers - one for the analysis and one for the data collection to be sent to the server. The analytical buffer works on the FIFO principle, keeping the last X records at all times. The upload buffer is progressively filled, the content is sent to the server when the capacity is full and the buffer is emptied.

- The communication module is responsible for the communication with the server (predominantly for sending the sensor data) and other devices in the system.

- The analyser is used to evaluate the collected samples and determine user status, using different algorithms such as neural networks and specialized algorithms.

\section{Communication}

Communication and early warning is crucial for such a system. Therefore, in a dangerous situation, it is necessary to ensure that the information is delivered to the desired location. It is also necessary for this system to minimize the mobile data and the battery itself. The exchange of information includes the sending of user data for the long-term analysis, the individual states of the user and the support (service - used to manage and operate the application) of the communication. The system communicates on several levels. For sending the user data and other communication with the server, the mobile Internet is used. In the same way, other communications with the server from the tablet part are also in progress. In the event of a tablet component in the system, the responsible person's tablet would create a Wi-Fi network through which the user would send the data about the status and location of the user. This network could be also used to communicate with the server where the tablet would work as a gateway and all the data on the server would go through it. As a Wi-Fi backup, in the case of large data or other 
Figure 3 Interaction of the components and application logic

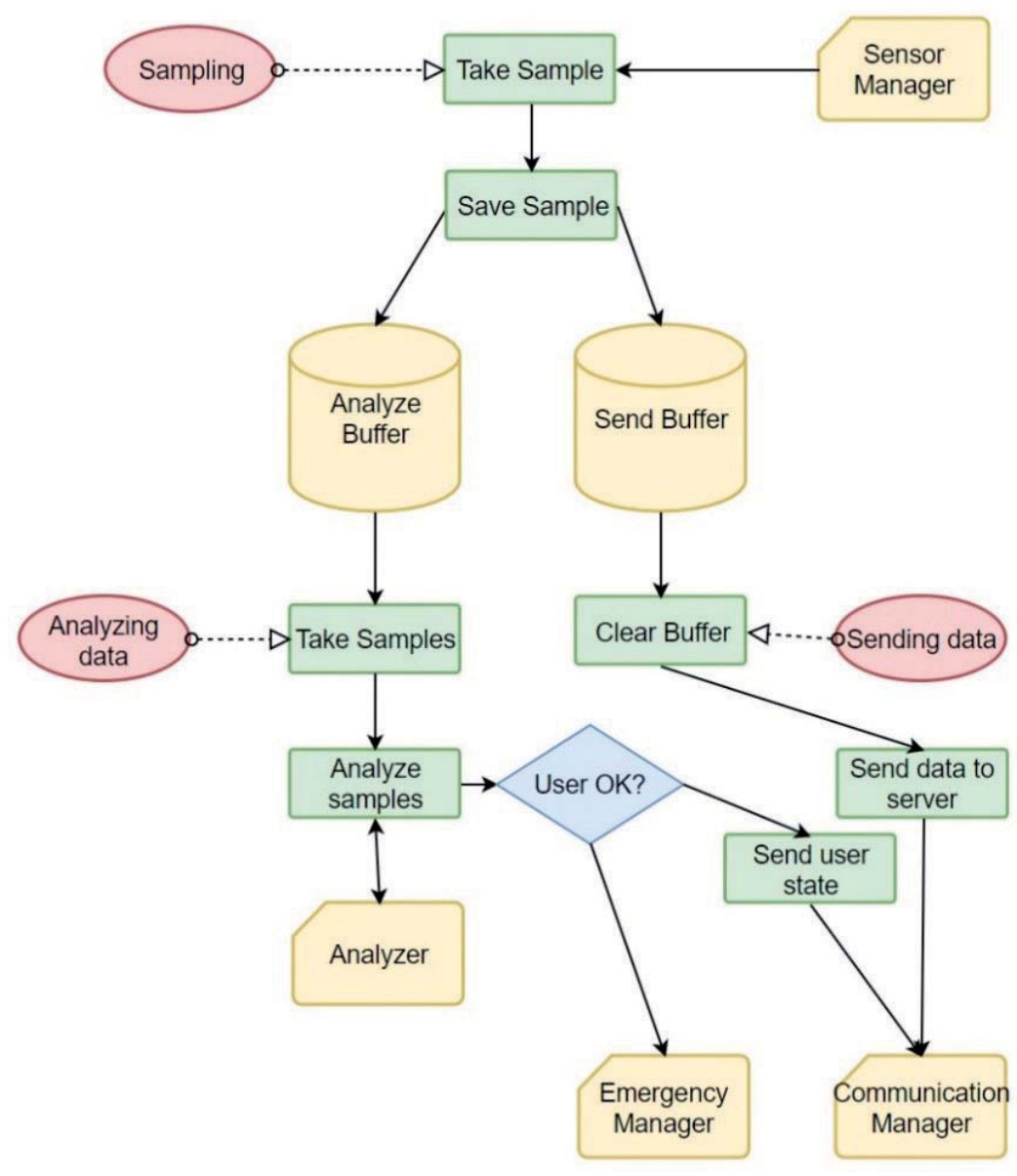

Source: own processing

burdens, Bluetooth communication would work. For the smallest data and computing load, the data are sent by using Flat buffers (Google library) that sends the data with the least added data. The data are converted to a range of bytes that are normally sent over the network. This format is used in all forms of communication. Calling for help would be made with all means, mobile internet (server), Wi-Fi (supervisor's tablet) and phone call itself or SMS (local rescue service).

\section{Neural networks for the fall detection}

The neural networks, as mentioned in the theoretical part of this study, are able to solve many problems if they are properly trained. One of their possible uses is the detection of walking abnormalities that could indicate a threat to the user based on device sensor data. These abnormalities may be the downfall of the user and the deterioration of his/ her health condition (e.g., malaise and rumbling due to fever). For the detection of falls, the forward neural network is used, the input of which includes both the accelerometer 
Figure 4 The use of the neural networks for the movement classification of a user

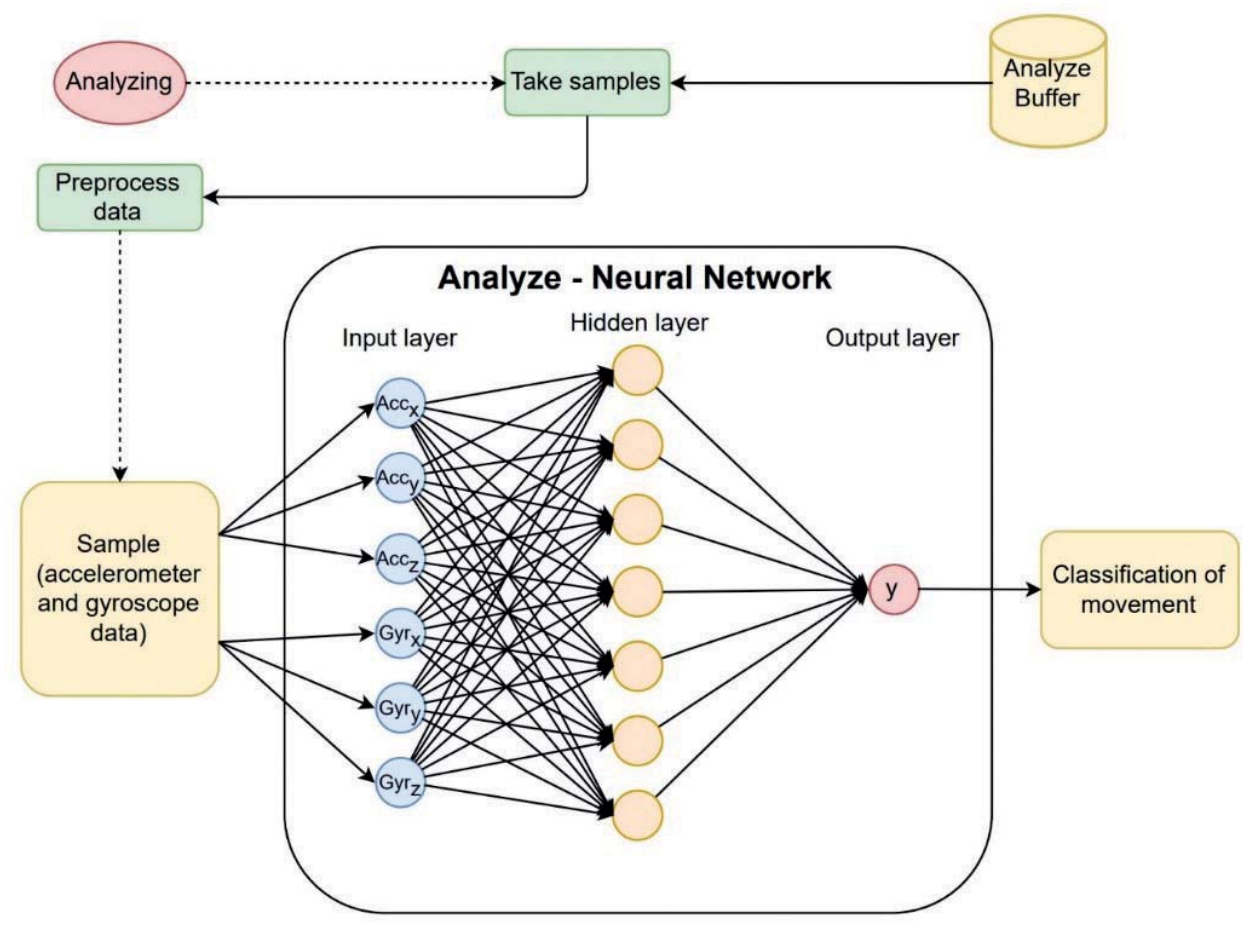

Source: own processing

data and gyroscope data. These data are acquired with a certain period; however, due to the non-real-time nature of the OS smartphones, it is necessary to transform these data before. Other modifications are transformations that aim to eliminate the effect of the rotation of the phone on motion detection itself (i.e. the way the user has the phone stored in his/her pocket). After the transformation, an analysis is carried out, the aim of which is the numerical classification of the movements themselves, which are then evaluated and it is decided whether the user is in the normal state. The process of the data acquisition, processing, and finally, the analysis are shown in Figure 4. External sensors (i.e. located on the user himself/herself) can supplement the internal sensors for greater accuracy (but these can limit users and reduce their comfort).

\section{Summary}

In this article, the concept of a system for the support of tourism people with disabilities was designed and described in order to make the best possible use of the facilities already owned by the tourists. The proposal also builds on the significant progress, currently being made in the development of artificial neural network technology and mobile device hardware itself. The system is designed so that most of its own solution is included in the program section and can be integrated with the existing HW. The primary focus of all research and development was the mobile app. It is an essential element of the system 
and contains critical algorithms. The architecture of the proposed solution enables its autonomous operation to provide user support and monitoring, even without the other components of the system. The protocols used and the suggested procedures (logic of the application core itself) further provide low data and energy performance. Another advantage is the ease of extension of the system itself and the connection to the mobile part. The main source for this concept was application framework developed during the research - WatchDog System. WatchDog consist of all described applications but without analysing algorithms. Its main purpose was collecting the data for this research. The platform can be later used in a production system, after adding all necessary algorithms and functions.

Several major issues emerged during the development of the system, which had to be solved in some way. The necessity of the mobile part is its practically real-time functionality. For the correct evaluation of the samples, it is necessary that the interval between the gained values is as constant as possible. This is difficult to resolve because the application does not have direct access to the hardware of the device. For this reason, the data collection function only takes the value of the sensor itself to ensure the most accurate period. The frequency of the data collection should be as high as possible, but this can easily lead to a rapid depletion of the plant's energy source, coupled with the need to analyse it. Therefore, it is necessary to find an optimal frequency, which will allow an efficient data analysis and will not burden equipment resources.

Future research should primarily focus on the most accurate evaluation and expansion of options in this area, in particular, by adding the detection of other threatening situations. In addition, the use of the external sensors in the form of wearables and their integration in the evaluation cycle itself can be another expansion of this research.

\section{Acknowledgements}

The financial support of the Specific Research Project "Information and Knowledge Management and Cognitive Science in Tourism" of FIM UHK is gratefully acknowledged. The authors wish to express their thanks to Jan Hruška, a FIM UHK student, who assisted with the graphical elements of this study.

\section{References}

Armitano, C. N., Clapham, E. D., Lamont, L. S., \& Audette, J. G. (2015). Benefits of Surfing for Children with Disabilities: A Pilot Study. Palaestra, 29, 31-35. DOI: 10.18666/PALAESTRA-2015-V29-I3-6912.

Bizjak, B., Knežević, M., \& Cvetrežnik, S. (2011). Attitude change towards guests with disabilities: Reflections from Tourism Students. Annals of Tourism Research, 38(3), 842-857. DOI: 10.1016/j. annals.2010.11.017.

Buhalis, D., \& Michopoulou, E. (2011). Information-enabled tourism destination marketing: Addressing the accessibility market. Current Issues in Tourism, 14(2), 145-168. DOI: 10.1080/13683501003653361. 
Chang, Y. C., \& Chen, C. F. (2012). Meeting the needs of disabled air passengers: Factors that facilitate help from airlines and airports. Tourism Management, 33(3), 529-536. DOI: 10.1016/j. tourman.2011.06.002.

Darcy, S. (2010). Inherent complexity: Disability, accessible tourism and accommodation information preferences. Tourism Management, 31(6), 816-826. DOI: 10.1016/j.tourman.2009.08.010.

Eichhorn, V., Miller, G., Michopoulou, E., \& Buhalis, D. (2008). Enabling Access to Tourism through Information Schemes. Annals of Tourism Research, 35(1), 189-210. DOI: 10.1016/j.annals.2007.07.005.

Figueiredo, E., Eusébio, C., \& Kastenholz, E. (2012). How Diverse are Tourists with Disabilities? A Pilot Study on Accessible Leisure Tourism Experiences in Portugal. International Journal of Tourism Research, 14(6), 531-550. DOI: 10.1002/jtr.1903.

Gillovic, B., \& McIntosh, A. (2015). Stakeholder perspectives of the future of accessible tourism in New Zealand. Journal of Tourism Futures, 1(3), 223-239. DOI: 10.1108/JTF-04-2015-0013.

Kim, W. G., Stonesifer, H. W., \& Han, J. S. (2012). Accommodating the needs of disabled hotel guests: Implications for guests and management. International Journal of Hospitality Management, 31(4), 1311-1317. DOI: 10.1016/j.ijhm.2012.03.014.

Law, R., Buhalis, D., \& Cobanoglu, C. (2014). Progress on information and communication technologies in hospitality and tourism. International Journal of Contemporary Hospitality Management, 26(5), 727-750. DOI: 10.1108/IJCHM-08-2013-0367.

Lee, B. K., Agarwal, S., \& Kim, H. J. (2012). Influences of travel constraints on the people with disabilities' intention to travel: An application of Seligman's helplessness theory. Tourism Management, 33(3), 569-579. DOI: 10.1016/j.tourman.2011.06.011.

Leung, D., Law, R., Hoof, H. V., \& Buhalis, D. (2013). Social Media in Tourism and Hospitality: a Literature Review. Journal of Travel $\mathcal{E}$ Tourism Marketing, 30, 3-22. DOI: 10.1080/10548408.2013.750919.

McKercher, B., Packer, T., Yau, M. K., \& Lam, P. (2003). Travel agents as facilitators or inhibitors of travel: perceptions of people with disabilities. Tourism Management, 24(4), 465-474. DOI: 10.1016/S0261-5177(02)00107-3.

Mothiravally, V., Ang, S., Baloch, G. M., Kulampalli, T. T., \& Geetha, S. (2014). Attitude and Perception of Visually Impaired Travelers: A Case of Klang Valley, Malaysia. Procedia - Social and Behavioral Sciences, 144, 366-377. DOI: 10.1016/j.sbspro.2014.07.306.

Nezakati, H., Amidi, A., Jusoh, Y. Y., Moghadasa, S., Aziza, Y. A., \& Sohrabinezhadtalemia, R. (2015). Review of Social Media Potential on Knowledge Sharing and Collaboration in Tourism Industry. Procedia - Social and Behavioral Sciences, 172, 120-125, DOI: 10.1016/j.sbspro.2015.01.344.

Oxley, P. R., \& Richards, M. J. (1995). Disability and transport: A review of the personal costs of disability in relation to transport. Transport Policy, 2(1), 57-65. DOI: 10.1016/0967-070X(95)93247-V.

Ozturk, Y., Yayli, A., \& Yesiltas, M. (2008). Is the Turkish tourism industry ready for a disabled customer's market? The views of hotel and travel agency managers. Tourism Management, 29(2), 382-389. DOI: 10.1016/j.tourman.2007.03.011.

Pagan, R. (2012). Time allocation in tourism for people with disabilities. Annals of Tourism Research, 39(3), 1514-1537. DOI: 10.1016/j.annals.2012.04.005.

Pásková, M., \& Zelenka, J. (2016). Social Responsibility Role in Tourism Sustainability. In P. Jedlička (Ed.), Proceedings of Hradec Economic Days (pp. 777-785).

Pásková, M., \& Zelenka, J. (2018). How Crucial is the Social Responsibility for Tourism Sustainability. Social Responsibility Journal, 15(4), 534-552. DOI: 10.1108/SRJ-03-2018-0057. 
Ray, M., \& Ryder, E. (2003). Ebilities tourism: an exploratory discussion of the travel needs and motivations of the mobility-disabled. Tourism Management, 24(1), 57-72. DOI: 10.1016/S02615177(02)00037-7.

Richards, V., Pritchard, A., \& Morgan, N. (2010). (Re)Envisioning tourism and visual impairment. Annals of Tourism Research, 37(4), 1097-1116. DOI: 10.1016/j.annals.2010.04.011.

Shaw, G., \& Coles, T. (2004). Disability, holiday making and the tourism industry in the UK: a preliminary survey. Tourism Management, 25(3), 397-403. DOI: 10.1016/S0261-5177(03)00139-0.

Shi, L., Cole, S., \& Chancellor, H. C. (2012). Understanding leisure travel motivations of travelers with acquired mobility impairments. Tourism Management, 33(1), 228-231. DOI: 10.1016/j.tourman.2011.02.007.

Small, J., \& Darcy, S. (2010). Tourism, Disability and Mobility. Tourism and Inequality: Problems and Prospects. In S. Cole \& N. Morgan (Eds.), Tourism and inequality: problems and prospects (pp. 1-20). CABI.

Small, J., Darcy, S., \& Packer, T. (2012). The embodied tourist experiences of people with vision impairment: Management implications beyond the visual gaze. Tourism Management, 33(4), 941-950. DOI: 10.1016/j.tourman.2011.09.015.

Smith, R. W. (1987). Leisure of disable tourists: Barriers to participation. Annals of Tourism Research, 14(3), 376-389. DOI: 10.1016/0160-7383(87)90109-5.

Tussyadiah, I. P., \& Zach, F. J. (2012). The role of geo-based technology in place experiences. Annals of Tourism Research, 39(2), 780-800. DOI: 10.1016/j.annals.2011.10.003.

UN. (2006). Convention on the Rights of Persons with Disabilities and Optional Protocol. Retrieved from http://www.un.org/disabilities/documents/convention/convoptprot-e.pdf.

Xiang, Z., Tussyadiah, I., \& Buhalis, D. (2015). Smart destinations: Foundations, analytics, and applications. Journal of Destination Marketing $\mathcal{E}$ Management, 4(3), 143-144. DOI: 10.1016/j. jdmm.2015.07.001.

Yau, M. K., McKercher, B., \& Packer, T. L. (2004). Traveling with a disability: More than an Access Issue. Annals of Tourism Research, 31(4), 946-960. DOI: 10.1016/j.annals.2004.03.007.

Zelenka J. (2012). Informační a komunikační technologie - perpetuum mobile cestovního ruchu (Information and Communication Technologies - Perpetual Motion of Tourism). Czech Journal of Tourism, 1(1), 5-17. 